\title{
Introduction
}

\section{Vertebral osteomyelitis and spinal epidural abscess}

\author{
Patrick C. Hsieh, M.D., ${ }^{1}$ John C. Liu, M.D. ${ }^{1}$ \\ and Michael Y. Wang, M.D. ${ }^{2,3}$
}

\begin{abstract}
${ }^{1}$ Department of Neurological Surgery, University of Southern California Keck School of Medicine, Los Angeles, California; and Departments of ${ }^{2}$ Neurological Surgery and ${ }^{3}$ Rehabilitation Medicine, University of Miami Miller School of Medicine, Miami, Florida
\end{abstract}

Infections of the vertebral column can result in vertebral osteomyelitis with or without epidural abscess. Moreover, spontaneous infection arising from the epidural space can occur, leading to epidural abscess. Whether these infections arise spontaneously or postoperatively, they can progress rapidly and cause severe neurological deficits. Despite the wide availability of intravenous antibiotics and advanced surgical techniques in recent decades, vertebral osteomyelitis and epidural abscess remain problematic and are major causes of debilitating neurological injury and morbidity. Appropriate treatment of vertebral osteomyelitis and epidural abscess is essential to prevent calamitous consequences, including paralysis and death.

Physicians and practitioners should first be aware of the natural history and risk factors associated with these diseases to perform appropriate diagnostic modalities. Speedy and accurate diagnosis is the first essential step to direct timely treatments. Although vertebral osteomyelitis and epidural abscess are considered to be rare historically, their incidence appears to be increasing in recent years compared with that in the first half of the 20th century. ${ }^{2}$ This disparity in epidemiology results from a number of factors, including improved neuroimaging capabilities, better awareness of these diseases, an increased number of elderly individuals, and a greater number of immunocompromised patients, from cancer survivors to individuals with human immunodeficiency virus (HIV) infection. At the same time, there is a growing rate of illicit drug

Please include this information when citing this paper: DOI: 10.3171/2014.6.FOCUS14293. abuse in the United States as well as a greater incidence of methicillin-resistant Staphylococcus aureus infections. Despite having sophisticated imaging techniques and laboratory studies, the rate of misdiagnosis at presentation for vertebral osteomyelitis and epidural abscess is still high, with an average rate of approximately $50 \%$. $^{3,5,7}$

Symptomatic vertebral osteomyelitis and epidural abscess with neurological deficits have long been considered surgical emergencies. The goal of surgery is to provide direct decompression of spinal cord and nerves to prevent neurological deterioration and reverse neurological deficits. Since local inflammation leading to thrombophlebitis or venous congestion is thought to be the mechanism of neurological injury in some cases, surgical debridement can also remove the inciting organisms and factors to reduce the risk of vascular-related neurological complications. On the other hand, the treatment of neurologically intact patients with vertebral osteomyelitis alone or minimal epidural abscess is quite controversial. Successful medical treatment for these types of cases has been reported, as have cases of failed medical treatment resulting in neurological decline., ${ }^{1,3,4,6,8}$ The scarcity of these cases along with the wide variation in clinical presentations makes it difficult to conduct any largescale observational studies. Furthermore, conducting a randomized study of treatment in these diseases raises ethical concerns because of the potential for progressive and devastating outcomes with the failure of treatment. Hence, physicians are largely dependent on anecdotal experience, animal studies, literature case reports, and uncontrolled clinical series to gain knowledge and treatment guidance for vertebral osteomyelitis and epidural abscess.

In this issue of Neurosurgical Focus, articles on the diagnosis, medical management, surgical treatment, and clinical outcomes related to vertebral osteomyelitis and spinal epidural abscess are included. We hope that readers will find pertinent information on the management of vertebral osteomyelitis and spinal epidural abscess from the articles in this issue.

(http://thejns.org/doi/abs/10.3171/2014.6.FOCUS14293)

\section{Disclosure}

Dr. Wang is a consultant for and holds a patent with DePuy Spine. Dr. Liu is a consultant for Medtronic. Dr. Hsieh is a consultant for Medtronic and DePuy Synthes. 


\section{References}

1. Akalan N, Ozgen T: Infection as a cause of spinal cord compression: a review of 36 spinal epidural abscess cases. Acta Neurochir (Wien) 142:17-23, 2000

2. Darouiche RO: Spinal epidural abscess. N Engl J Med 355: 2012-2020, 2006

3. Davis DP, Wold RM, Patel RJ, Tran AJ, Tokhi RN, Chan TC, et al: The clinical presentation and impact of diagnostic delays on emergency department patients with spinal epidural abscess. J Emerg Med 26:285-291, 2004

4. Lu CH, Chang WN, Lui CC, Lee PY, Chang HW: Adult spinal epidural abscess: clinical features and prognostic factors. Clin Neurol Neurosurg 104:306-310, 2002
5. Patel AR, Alton TB, Bransford RJ, Lee MJ, Bellabarba CB, Chapman JR: Spinal epidural abscesses: risk factors, medical versus surgical management, a retrospective review of 128 cases. Spine J 14:326-330, 2014

6. Siddiq F, Chowfin A, Tight R, Sahmoun AE, Smego RA Jr: Medical vs surgical management of spinal epidural abscess. Arch Intern Med 164:2409-2412, 2004

7. Tang HJ, Lin HJ, Liu YC, Li CM: Spinal epidural abscessexperience with 46 patients and evaluation of prognostic factors. J Infect 45:76-81, 2002

8. Wheeler D, Keiser P, Rigamonti D, Keay S: Medical management of spinal epidural abscesses: case report and review. Clin Infect Dis 15:22-27, 1992 